\title{
Removal of pentachlorophenol in a rhizotron system with ryegrass (Lolium multiflorum)
}

\author{
C. Urrutia ${ }^{1,2}$, O. Rubilar², C. Paredes 3 , E. Benítez ${ }^{4}$, R. Azcón ${ }^{4}$ and M. C. Diez ${ }^{2,5^{*}}$.
}

\begin{abstract}
'Programa de Doctorado y Magíster en Ciencias de Recursos Naturales, Universidad de La Frontera, Avenida Francisco Salazar, 01145 Temuco, Chile. ${ }^{2}$ Environmental Biotechnology Center, Scientific and Technological Bioresource Nucleus (BIOREN), Universidad de La Frontera, P.O. Box 54-D, Temuco, Chile. ${ }^{3}$ Center of Plant-Soil Interaction and Natural Resources Biotechnology, Scientific and Technological Bioresource Nucleus (BIOREN), Universidad de La Frontera, Casilla 54-D, Temuco, Chile. ${ }^{4}$ Department of Environmental Protection, Zaidin Experimental Station, CSIC, Granada, Spain. ${ }^{5}$ Department of Chemical Engineering, Iniversidad de la Frontera, Temuco, Cile.*Corresponding author: cristina.diez@ufrontera.cl
\end{abstract}

\begin{abstract}
Degradation of pentachlorophenol (PCP) in the rhizosphere of Lolium multiflorum (ryegrass) was studied in an Andisol of southern Chile. A rhizotron system was designed to evaluate the effect of different PCP concentrations $\left(50,100\right.$ and $\left.250 \mathrm{mg} \mathrm{kg}^{-1}\right)$ on plant biomass, organic acid exudation, dehydrogenase and the $\beta$-glucosidase activity of L. multiflorum. Moreover, the microbial biomass was estimated using a molecular technique in different sections of rhizotrons. More than $96 \%$ of PCP was removed in the rhizotron system by adsorption in the soil and degradation by the rhizosphere of L. multiflorum. The plant biomass decreased when the PCP concentration was increased in the soil, the biomass for the treatment with $250 \mathrm{mg} \mathrm{kg}^{-1}$ being significantly lower. The estimation of the microbial biomass and $\beta$-glucosidase activity in the soil was not affected when the PCP concentration was increased, indicating a low toxicity of the contaminant due to its lesser availability. However, the dehydrogenase activity decreased when increasing the PCP concentration, showing negative effects on microorganisms. The organic acid exudates varied during the incubation time, influenced by the stress of the different treatments and the distribution of roots. Therefore, Lolium multiflorum is a promising candidate for designing field scale phytoremediation processes.
\end{abstract}

Keywords: Pentachlorophenol, phytoremediation, Lolium multiflorum, rhizosphere 


\section{Introduction}

Pentachlorophenol (PCP) is a pollutant with a significant environmental impact not only on the ecosystem, but also on human health. The most commonly used methods for removing PCP from polluted soils are disposal in landfills, soil washing and chemical extraction. Many of these strategies are expensive and are not proven to be effective in eliminating contaminants from the environment Bioremediation, an alternative biological method, that includes phytoremediation, has demonstrated its effectiveness, and this biotechnology will be our focus.

In phytoremediation the rhizosphere is very important place were pollutant degradation occurs, due to interaction between plants roots and soil microorganisms and takes place (Dams et al,2007). In the rhizosphere, pollutant degradation is stimulated by the release of root exudates, plant enzymes and soil microorganisms. The composition and concentration of them can vary depending on plant species (Zheng and Zhang 2000; He et al. 2005). Plant roots also improve the adsorption of pollutants in the soil, increasing their bioavailability, thereby generating several changes in the soil (Dams et al. 2007). These changes can be detected by measuring microbialorigin enzymes as they provide an indication of quality changes in contaminated soils. Similarly, $\beta$-glucosidase activity varies with soil management and has been proposed as an indicator of soil quality because it provides an early sign of changes in organic matter status and its turnover (Ndiaye et al. 2000; Madejón et al. 2001). In addition, dehydrogenase activity has been considered a measure of the total oxidative activity of soil microflora, and therefore of the metabolic activity of soil (Nannipieri et al, 2002).

He et al. (2005) and Nakamura et al. (2004) showed that the rhizosphere effect of Lolium perenne L. and Allium tuberosum Rottler effectively influences PCP degradation in soil, suggesting that the rhizosphere associated with microbial biomass increases with the ability to eliminate this compound. He et al. (2009) suggested that root exudates induced modifications to microbial communities in the PCP contaminated rhizosphere. To improve our understanding of this phenomenon, further research is necessary to provide clarity of the plant-soil-microbe interactions developed within this study.

Therefore, the aim of this study was to evaluate the degradation of PCP in the rhizosphere of Lolium multiflorum (ryegrass). In this assay, Lolium multiflorum was planted in the soil contaminated with different PCP concentrations and disposed in a rhizotron system composed of micro suctions tubes to investigate the chemical changes of the rhizosphere by the localized extraction of soil solution near the root. Furthermore, soil enzyme activities and bacterial biomass were determined via real time PCR.

\section{Materials and Methods}

\subsection{Preparation of soil}

An Andisol collected from the Temuco Series located in southern Chile $\left(38^{\circ} 42^{\prime} \mathrm{S}, 73^{\circ} 35^{\prime} \mathrm{W}\right.$ ) was used for the experiments. This soil was collected at a depth of $0-20 \mathrm{~cm}$ and the pre-treatment involved sieving to select a particle size under $2 \mathrm{~mm}$ and air-drying. The major physic-chemical properties of the soil are; $\mathrm{pH}$ (in water) $=5.70 \pm 0.10 ; \mathrm{N}(\%)=0.72 \pm 0.02 ; \mathrm{C}$ $(\%)=8.06 \pm 0.95 ; \mathrm{P}\left(\mathrm{mg} \mathrm{kg}^{-1}\right)=15.0 \pm 0.95 ; \mathrm{MO}(\%)$ $14.0 \pm 1.68 ; \mathrm{C} / \mathrm{N}=11.0 \pm 1.25$, values of mean $(\mathrm{n}=3) \pm$ standard deviation.

The soil was spiked with a stock solution of PCP (Aldrich, 98\% purity) diluted in acetone to reach a concentration of 50,100 or $250 \mathrm{mg} \mathrm{PCP} \mathrm{kg}^{-1}$ soil, homogenized by vigorous shaking and kept under a fume hood for $12 \mathrm{~h}$ to evaporate the solvent. 


\subsection{Seed preparation}

Seeds of Lolium multiflorum were used to evaluate PCP degradation. The seeds were sterilized in $2 \% \mathrm{v}$ $\mathrm{v}-1$ sodium hypochlorite solution for $20 \mathrm{~min}$, and then washed for $30 \mathrm{~min}$ with sterilized water. The seeds were incubated at $25^{\circ} \mathrm{C}$ in germination trays of $18 \mathrm{x}$ $12 \times 6 \mathrm{~cm}$, containing moist autoclaved Whatman no. 44 filter paper (Rattray et al. 1995). After 2 weeks, the germinated seeds were placed on 4 liter plastic pots containing Taylor and Foy nutritive solution (Taylor and Foy 1985). The solution was changed after the first week and maintained under periodic aeration in a controlled temperature chamber at $20 \pm 2{ }^{\circ} \mathrm{C}$ for 2 weeks.

\subsection{Rhizotron assay}

The assays were performed in triplicate using the rhizotron system of $33 \times 11.6 \times 2 \mathrm{~cm}$. The rhizotrons were filled with $620 \mathrm{~g}$ of soil contaminated with different PCP concentrations $(0,50,100$ or $250 \mathrm{mg}$ $\left.\mathrm{kg}^{-1}\right)$. Six ryegrass plants previously grown in Taylor and Foy nutritive solution with a root length of approximately $15 \mathrm{~cm}$, were placed in the rhizotron system. Five micro suction tubes $3 \mathrm{~mm}$ in diameter were installed around the plant root to obtain root exudates (malic acid, succinic acid and citric acid). Further, control treatments with unplanted soil, with different PCP concentrations, and planted soil without PCP concentration were developed for comparative effect. Each experiment was conducted in triplicate.

All rhizotrons were incubated at $20 \pm 2{ }^{\circ} \mathrm{C}$ and their water holding capacity (WHC) controlled at $60 \%$ for 10 days. The root exudates were periodically measured at 2, 4, 6, 8 and 10 days. At the end of the experiment, the rhizotrons were divided into three sections of $11 \mathrm{~cm}$ depth each: top zone (section 1), central zone (section 2) and bottom of rhizotron (section 3) in order to determine the effect of root on the PCP degradation. In each section, the residual PCP concentration, enzymatic assays (dehydrogenase and $\beta$-glucosidase) and microbial estimates were determined. In addition, the plants were collected to determine the root length and aerial and root biomass quantification.

\subsection{Plant biomass}

Plant growth was evaluated by biomass (aerial and roots) evaluation on the basis of dry weight at $80^{\circ} \mathrm{C}$ for 24-48 h. The results were expressed by the following equations:

$\%$ relative mass $=$ treated plant dry weight $/$ control plant dry weight $\mathrm{x} 100(E c .1)$

\subsection{Extraction and analysis of $P C P$}

The PCP extraction from soil was performed as described by Soto-Córdoba et al. (2001). The procedure was performed as follows: i) $4 \mathrm{~g}$ of soil were extracted with hexane for about 16 hours in a soxhlet extractor system, ii) the samples were evaporated at $65^{\circ} \mathrm{C}$ using a rotavapor under reduced pressure, iii) the sample was re-suspended in $5 \mathrm{~mL}$ of methanol HPLC grade and filtered through a $0.45 \mu \mathrm{m}$ membrane and iv) an aliquot of the organic phase was used for analysis.

Residual PCP was determined by high performance liquid chromatography (HPLC) with an instrument equipped with a Merck-Hitachi L-7100 pump, a Rheodyne 7725 injector with a $20 \mu \mathrm{L}$ loop, a MerckHitachi L-7455 diode array detector operating at $215 \mathrm{~nm}$, and a Hitachi D-7000 data processor. A Lichrosphere $60 \mathrm{RP}$ select B $250 \mathrm{~mm}$ x $4 \mathrm{~mm}$ column of $5 \mu \mathrm{m}$ particle size with a LichroCART 4-4 guard column (Merck) was used. The mobile phase consisted of acetonitrile and phosphoric acid $(1 \%$ aqueous solution) $1: 1\left(\mathrm{v} \mathrm{v}^{-1}\right)$ with a flow rate of $1 \mathrm{ml} \mathrm{min}^{-1}$ (PCP retention time was $12 \mathrm{~min})$. Instrument calibrations and quantifications were performed against the pure reference standard $\left(0.05-5 \mathrm{mg} \mathrm{L}^{-1}\right)$. The procedure described was checked for recovery (which ranged from $86-100 \%$ ). The detection limit was $0.03 \mathrm{mg} \mathrm{l}^{-1}$, considering a noise-to-signal ratio greater than 2 . 


\subsection{Collection and quantification of root exudates}

Exudates were collected every two days until day 10 , and frozen immediately after extraction. The concentration of organic acid (malic acid, succinic acid and citric acid) exudates was analyzed by HPLC. The samples were filtered through a $0.45 \mu \mathrm{m}$ membrane before injection $(20 \mu \mathrm{L})$ in the HPLC equipment. HPLC analyses were performed with a Merck Hitachi L-7100 pump, a Rheodyne 7725 injector with $20 \mu \mathrm{L}$ loop diode array detector. The detection was set up at $210 \mathrm{~nm}$ and the column was a reverse phase (Merck, LiChrospher 100 RP-18. $5 \mu \mathrm{M}$ ). The mobile phase consisted of phosphoric acid $200 \mathrm{mM}, \mathrm{pH} 2.1$ worked at $25^{\circ} \mathrm{C}$ delivered at a flow rate of $2 \mathrm{~mL} \mathrm{~min}^{-1}$, at room temperature (about $22{ }^{\circ} \mathrm{C}$ ). Standard solutions were prepared from a mixture of organic acids, to identify organic acids present in the exudates, which was done by comparing the retention times with standards.

\subsection{Enzymatic activities}

Dehydrogenase activity was determined using Mersi and Schinner (1991) method modified by Garcia et al. (1997). One gram of soil was incubated for $20 \mathrm{~h}$ at $25{ }^{\circ} \mathrm{C}$ with $0.2 \mathrm{~mL}$ of $0.4 \%$ 2-p-iodophenyl-3-pnitrophenyl-5 tetrazolium chloride (INT) as a substrate. Iodonitrotetrazolium formazan (INTF) produced in the reduction of INT was extracted with a mixture of acetone:tetrachloroethene (1.5:1), and measured in a spectrophotometer at $490 \mathrm{~nm}$. Assays without soil and without INT were performed simultaneously as controls. The enzymatic activity is expressed in ug INTF $\mathrm{g} \mathrm{h}^{-1}$.

For the determination of $\beta$-glucosidase, $0.5 \mathrm{~mL}$ of 0.05 M 4-nitrophenyl- $\beta$-D-glucanopyranoside (PNG) was used as substrate (Tabatabai 1982). Soil samples (0.5 g) were incubated at $37^{\circ} \mathrm{C}$ for $2 \mathrm{~h}$ with $2 \mathrm{~mL}$ of maleate buffer at $\mathrm{pH}$ 6.5. The samples were kept at $2{ }^{\circ} \mathrm{C}$ for $15 \mathrm{~min}$ to stop the reaction, and the p-nitrophenol (PNP) produced was extracted and determined at 398 $\mathrm{nm}$ (Nannipieri et al. 1982). The enzymatic activity is expressed in ug PNP $\mathrm{g} \mathrm{h}^{-1}$.

\subsection{Soil-DNA extraction and real-time PCR assay}

In this study, the total DNA was extracted from $0.5 \mathrm{~g}$ soil following the manufacturer's instructions for the MoBio UltraClean Soil DNA Isolation kit (MoBio Laboratories Inc., Solana Beach, CA, USA). To remove trace concentrations of PCR inhibitors, the second step (Inhibitor Removal Solution) was repeated. The DNA samples were checked for concentration and quality using the NanoDrop1 ND-1000 Spectrophotometer (NanoDrop Technologies, Wilmington, Delaware; USA).

Real-time PCR was performed to quantify the number of 16S rRNA copy in triplicate soil-DNA extracts. Universal specific primers for V3 hypervariable regions of 16S rRNA of eubacteria P1 and P2 (Muyzer, Dewaal, \& Uitterlinden 1993) were used. Each $21 \mu \mathrm{L}$ PCR reaction contained from 2 to $5 \mathrm{ng}$ of the DNA, $10.5 \mathrm{~mL} 2 \times$ iQ SYBR Green Supermix (Bio-Rad, Munich, Germany), and $400 \mathrm{nM}$ each primer. For each extracted DNA, real-time PCR experiments were conducted three times with the threshold cycle $(\mathrm{Ct})$ determined in triplicate. The real-time PCR program consisted of $1.5 \mathrm{~min}$ at $50{ }^{\circ} \mathrm{C}$ for carryover prevention, $15 \mathrm{~min}$ at $95{ }^{\circ} \mathrm{C}$ for enzyme activation, followed by 35 cycles of $15 \mathrm{~s}$ at $95{ }^{\circ} \mathrm{C}, 30 \mathrm{~s}$ at $55^{\circ} \mathrm{C}$ and $30 \mathrm{~s}$ at $72{ }^{\circ} \mathrm{C}$, when the fluorescence signal was measured. PCR amplification procedure was checked with a heat dissociation protocol (from $70{ }^{\circ} \mathrm{C}$ to $100{ }^{\circ} \mathrm{C}$ ) after the final PCR cycle. The DNA copy number was quantified on an iQ5 thermocycler using iQ5-Cycler software (Bio-Rad, Munich, Germany). The standard curve was generated by using a plasmid recombinant containing a copy of $16 \mathrm{~S}$ rRNA fragment. The curve was drawn by plotting the $\mathrm{Ct}$ value as a function of the log of the copy number of 10 -fold dilution serial of plasmid DNA. As Ct values may vary slightly between experiments, parallel sets of the three dilution series of pure standard DNA were run in all experiments. The relationship between $\mathrm{Ct}$ and the target gene copy number, and the copy numbers of the real-time standard were calculated as described by Qian et al. (2007). 


\subsection{Data analyses}

Experiments were conducted using three independent replicates. PCP residual measurements in the different treatments were subjected to an analysis of variance (one-way ANOVA), and the averages were compared by Tuckey`s test at $p \leq 0.05$, to identify statistical differences among section of rhizotron at the same treatment. Relative mass were compared by Tuckey`s test at $\mathrm{p} \leq 0.05$, to identify statistical differences among treatments with the control at the end of assay.

Microbial activities measurements in the different treatments at the end of assay were subjected to a one-way ANOVA and the averages were compared by Tuckey`s test at $p \leq 0.05$, to identify significant effects of sampling treatments in the same treatments in different sections of rhizotron and among treatments at the same section of rhizotron.

\section{Results and Discussion}

\subsection{PCP removal}

High PCP removal (>96\%) was observed in the different sections of rhizotrons with 50,100 and $250 \mathrm{mg} \mathrm{kg}^{-1}$ of initial PCP concentration (Figure 1). ). In the different sections of the rhizotrons, significant differences were observed only in the treatment with $250 \mathrm{mg} \mathrm{kg}^{-1}$ of PCP between section 3 and the other sections.

These results can be attributed to the absence of roots in section 3 of the rhizotron. In this respect, only the root growth in the rhizotron with $250 \mathrm{mg} \mathrm{kg}^{-1}$ did not reach section 3, with the root growth being inhibited by PCP concentration; consequently, there was less removal of PCP (Table 1). These results are consistent with the study performed by Dams et al. (2007), where it was demonstrated that root length of Triticum aestivum was affected by $100 \mathrm{mg} \mathrm{kg}^{-1}$ of PCP compared to the root length for plants in the absence of PCP. Therefore, our study suggests that PCP concentrations greater than $100 \mathrm{mg} \mathrm{kg}^{-1}$ inhibit root growth of Lolium multiflorum generated a reduced removal of PCP due to decreased root growth.

These results agree with several studies (He et al. 2005; Dams et al. 2007; He et al. 2009), which have demonstrated that PCP degradation in soil planted with ryegrass depended on the proximity of the roots to the contaminated soil. He et al. (2005) attributed this effect to interactions of PCP with root exudates and the soil microbial community.

The PCP removal in unplanted soil is presented in Figure 2. In soil with $50 \mathrm{mg} \mathrm{kg}^{-1}$ of removed PCP concentration, there were $17.35 \mathrm{mg} \mathrm{kg} \mathrm{kg}^{-1}$ of $\mathrm{PCP}$, corresponding to $34.5 \%$, while in an unplanted soil with $100 \mathrm{mg} \mathrm{kg}^{-1}$ and $250 \mathrm{mg} \mathrm{kg}^{-1}$ they were $36 \%$ and $38 \%$, respectively. PCP removal in unplanted soil is attributed mainly to PCP degradation by indigenous microorganisms and the adsorption process.

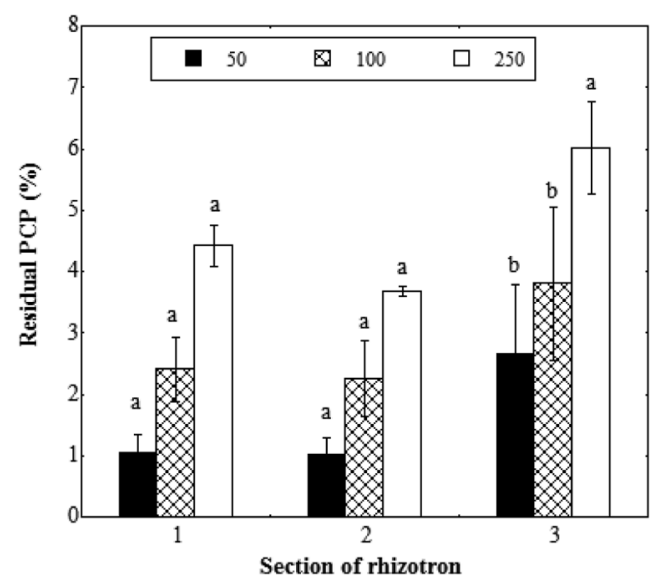

Figure 1. Residual PCP (\%) in the soil contaminated with 50,100 and $250 \mathrm{mg} \mathrm{kg}^{-1}$ of PCP in the different sections of rhizotron, during the degradation time. Each value is the mean of three replicates with error bars showing the standard deviation of the mean. Bars indicated by different letters show significant differences among section of rhizotron at the same PCP concentration. 
In this context, in most studies on PCP removal in Andisols, the principal mechanism is adsorption (Navia et al. 2003; Diez et al. 2005; Cea et al. 2005; Rubilar et al. 2011) Rubilar et al. (2011) demonstrated that in an Andisol contaminated with $250 \mathrm{mg} \mathrm{kg}^{-1}$ of PCP, $55.7 \pm 6.3 \%$ was removed, where the $41.2 \pm$ $2.4 \%$ (measured in sterile soil) due to the adsorption process, with the highest adsorption rate during the first 7 days of incubation Cea et al. (2005) demonstrated that Chilean Andisols are particularly efficient sorbents for chlorophenols, mainly for allophane-ferrihydrite associations found in organic matter accumulated through the formation of stable complexes with $\mathrm{FeOH}$ and $\mathrm{AlOH}$, so that these will allow hydrogen bond formation between hydroxyl groups and pentachlorophenol.

Table 1. Root long of Lolium multiflorum planted in soil contaminated with different PCP concentrations.

\begin{tabular}{cc}
\hline $\begin{array}{c}\text { Soil contaminated with initial PCP } \\
\text { concentration }\left(\mathrm{mg} \mathrm{kg}^{-1}\right)\end{array}$ & Root long $(\mathrm{cm})^{\mathrm{a}}$ \\
\hline 0 & $28.0 \pm 1.2$ \\
50 & $26.0 \pm 0.9$ \\
100 & $24.0 \pm 1.1$ \\
250 & $15.0 \pm 0.4$ \\
\hline
\end{tabular}

${ }^{\text {a }}$ Value of mean $(n=3) \pm$ standard deviation

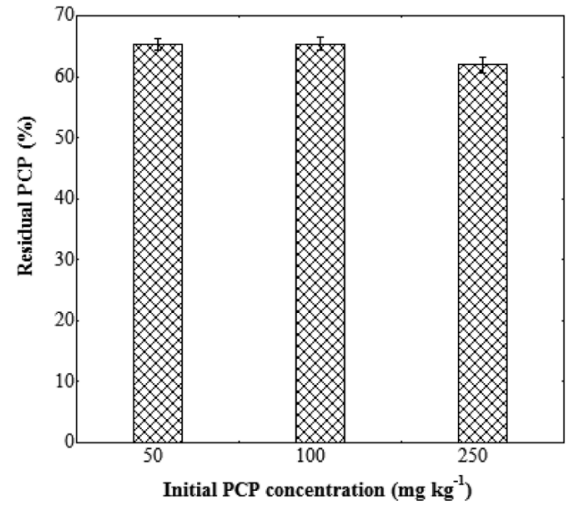

Figure 2. Residual PCP (\%) in the unplanted soil contaminated with 50,100 and $250 \mathrm{mg} \mathrm{kg}^{-1}$. Each value is the mean of three replicates with error bars showing the standard deviation of the mean.

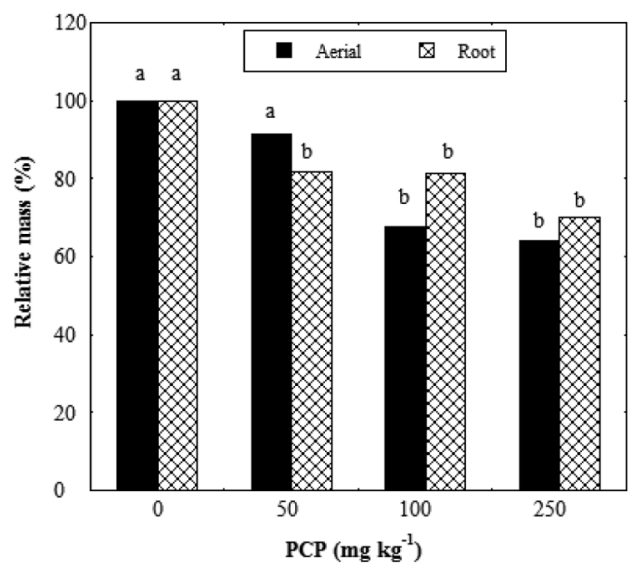

Figure 3. Plant biomass (aerial and root) in a rhizotron with a total of 6 Lolium multiflorum (ryegrass) expressed in relative mass (\%) to different PCP initial concentrations. Bars indicated by different letters show significant differences among treatments with the control at the end of assay. 


\subsection{Effect of PCP concentration on plant biomass of Lolium multiflorum}

Aerial and root plant biomass were measured after 10 days planted in PCP-contaminated soil (Figure 3). No significant differences between control treatment and the $50 \mathrm{mg} \mathrm{kg}^{-1}$ of PCP concentration were observed for the aerial biomass. However, significant differences were obtained between the control sample and treatments with 100 and $250 \mathrm{mg} \mathrm{L}^{-1}$. The same effect was found in studies performed by Dams et al. (2007) with Triticum aestivum, demonstrating that a PCP concentration of $100 \mathrm{mg} \mathrm{kg}^{-1}$ decreased plant growth.

A similar effect was observed in the root biomass of Lolium multiflorum mainly in the thickness of the roots, with the dry weight of root being lowest in the rhizotron system with the highest PCP concentration. Significant differences were found between the control treatment and the other treatment. However, no significant differences among different PCP concentrations (50, 100 and $250 \mathrm{mg} \mathrm{kg}^{-1}$ ) were observed.

\subsection{Effect of PCP concentration on enzymatic activities of soil}

The dehydrogenase enzyme is very often considered a reliable indicator of the active microbial biomass in soil, the activity of which depends on the survival of the living microbial cell (Trasar-Cepeda et al) 2000). Therefore, it is very sensitive to PCP contamination (Diez et al. 2006). The dehydrogenase activity PCPcontaminated soil decreased as the PCP concentration increased, especially in the rhizotron with an initial PCP concentration of $250 \mathrm{mg} \mathrm{kg}^{-1}$ (Figure 4). This suggested that although the PCP concentration was lower at the end of the assay, the soil microbes had not fully recovered from initial toxic responses of PCP. These results agree with Diez et al. (2006), who showed that dehydrogenase activity is affected further by PCP concentrations. In addition, McGrath and Singleton (2000) reported that, dehydrogenase activity decreased considerably in soils contaminated with PCP, although the PCP residual concentration was less than $2 \mathrm{mg} \mathrm{kg}^{-1}$ in soil after 6 weeks of incubation. This effect can be attributed to the toxicity of PCP degradation product. In this context, Rubilar et al. (2007) demonstrated that the main metabolite of pentachlorophenol degradation in soil is the pentachloroanisole. However, this compound is subsequently degraded by soil microorganisms. Besides, the dehydrogenase activity was not affected with respect to the different depths of rhizotrons in treatments of PCP at 0 and $50 \mathrm{mg} \mathrm{kg}^{-1}$. This effect could be attributed to that the root length was detected in the three sections of rhizotron. Different behavior was demonstrated in the treatment with 100 and 250 $\mathrm{mg} \mathrm{kg}^{-1}$ where the highest dehydrogenase activity was detected in the third section of rhizotron. In this case the high activity in section 3 of rhizotron could be attributed to a high accumulation of radical exudates (malic acid).

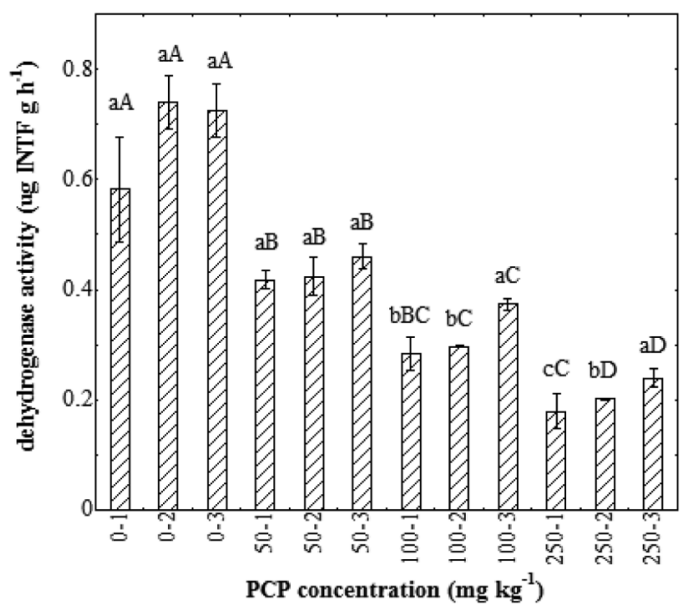

Figure 4. Dehydrogenase activity in the soil contaminated with 50,100 and $250 \mathrm{mg} \mathrm{kg}^{-1}$ of PVP in the different sections of rhizotron, during the degradation time. Each value is the mean of three replicates with error bars showing the standard deviation of the mean. Bars indicated by different capital or lower case letters show significant effects of sampling treatments in the same treatment in different sections of rhizotron and among treatments at the same section of rhizotron. 


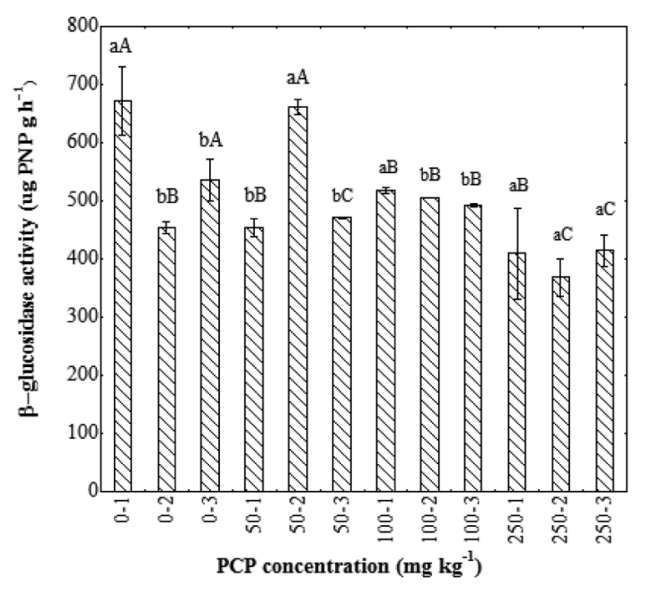

Figure 5. $\beta$-Glucosidase activity in the soil contaminated with 50, 100 and $250 \mathrm{mg} \mathrm{kg}^{-1}$ of PCP in the different sections of rhizotron, during the degradation time. Each value is the mean of three replicates with error bars showing the standard deviation of the mean. Bars indicated by different capital or lower case letters show significant effects of sampling treatments in the same treatment in different sections of rhizotron and among treatments at the same section of rhizotron.

The other enzyme evaluated was $\beta$-glucosidase as it has been proposed as a soil quality indicator, since it provides indications of changes in organic matter in the soil (Debosz et al. 1999). $\beta$-glucosidase activity is shown in Figure 5. In general, lower activities were observed in treatment contaminated with $250 \mathrm{mg} \mathrm{kg}^{-1}$ of PCP compared to the control in the three sections of rhizotron $(p \leq 0.05)$. In addition, $\beta$-glucosidase activity in control treatment without PCP the values were significantly higher in section (1 and 3 ) than rhizotrons contaminated with 50 and $100 \mathrm{mg} \mathrm{kg}^{-1}$ of $\mathrm{PCP}$ at the end of assay. This result is consistent with studies of Moreno et al. (2011), who found a negative effect of herbicides on $\beta$-glucosidase activity.

\subsection{Production of organic acids exuded by roots of Lolium multiflorum}

Malic acid, succinic acid and citric acid exuded by roots of L. multiflorum are shown in Figure 6.

Malic acid was detected throughout the entire incubation time for rhizotron with 100 and $250 \mathrm{mg} \mathrm{kg}^{-1}$ of PCP, increasing as time went on and being highest in the rhizotron with $250 \mathrm{mg} \mathrm{kg}^{-1}$ of PCP (Figure 6a); by contrast, the malic acid production was detected from day 6 in the control rhizotron and malic acid was detected only on days 8 and 10 in the rhizotron with $50 \mathrm{mg} \mathrm{kg}^{-1}$.

Succinic acid production was detected in all the rhizotrons with and without PCP. However, the results showed that the exudation of succinic acid was changeable in response to different PCP concentration stresses (Figure 6b).

Citric acid was detected in all treatments with and without PCP from the first day; it decreased for each treatment until it was not detected in any treatment on day 10 (Figure 6c).

Exudation of organic acid depends on diverse soil processes, such as plant metabolism, pollutant detoxification, nutrient available, soil composition, etc. It is difficult to determine the role of organic acid in phytoremediation due to the influence of many factors during their measurement, such as solid phase sorption/desorption reactions, complexation reactions, leaching and microbial degradation (Morita et al. 2004). The results showed that the exudation of organic acid was changeable in response to PCP concentration stress. Among the three organic acids detected in the experiment, malic acid showed the highest concentration in the soil, being exuded mainly in the rhizotron with the highest PCP concentration. Therefore, this organic acid could be important in controlling phytotoxity induced by PCP concentration. Walton et al. (1994) demonstrated that plants may respond to chemical stress by increasing or changing 
the exudation radical affecting the microfloral composition or activity of the rhizosphere, being capable of degrading toxicants. In the same way, Amellal et al. (2002) and Ouvrard et al. (2006) demonstrated that plants subjected to chemical stress can change soil properties, varying the bioavailability of contaminants in the soil. However, we must consider that there might be other factors that affect the exudation of organic acids. With these results, the variation of exudates among the three treatments with the addition of PCP and control can be achieved, reflecting a change in the responses of ryegrass to the different environmental conditions to which they have been subjected, which can in turn influence soil decontamination processes.
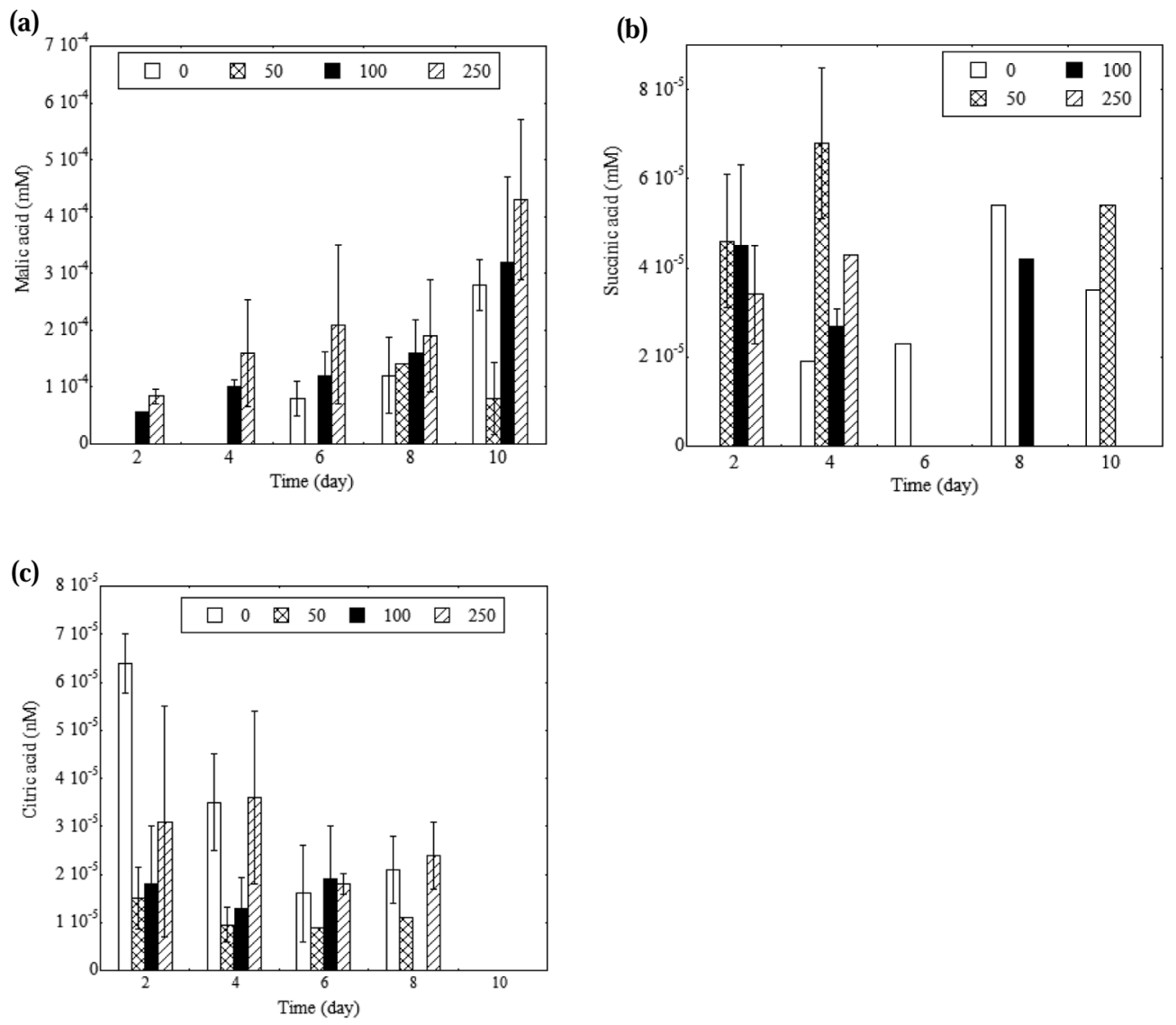

Figure 6. Exudation radical of malic acid (a), succinic acid (b) and citric acid (c) in the soil contaminated with 50, 100 and $250 \mathrm{mg} \mathrm{kg}^{-1}$ of PCP in the different sections of rhizotron, during the degradation time. Each value is the mean of three replicates with error bars showing the standard deviation of the mean. 


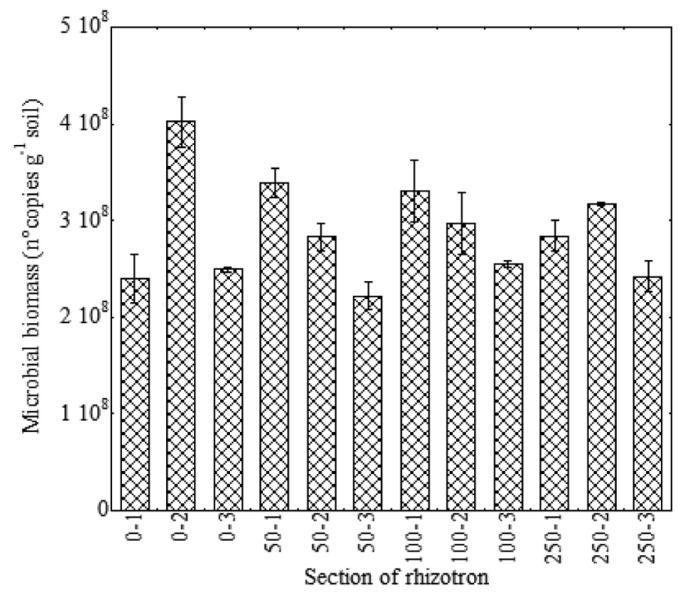

Figure 7. Estimation of the microbial biomass in the soil of PCP with 50, 100 and $250 \mathrm{mg} \mathrm{kg}^{-1}$ concentration in the different sections of rhizotron, during the degradation time. Each value is the mean of three replicates with error bars showing the standard deviation of the mean.

\subsection{Real-time quantitative $P C R$}

The estimation of the bacterial biomass was not affected by increasing the PCP concentration (Figure 7). Instead, the lowest quantity of copies detected in section 3 of the rhizotron are more likely associated with the lowest amounts of roots in this section than with the effect of PCP concentration (Figure 7). Studies conducted by $\mathrm{He}$ et al. (2005) demonstrated that microbial biomass was the largest in root proximity; as a result, the most effective PCP degradation, presumably due to the complementary effects between roots and associated microbial activity.

With respects to the different depths of rhizotron, the trend was not always the same for each treatment, which can be attributed to the sensitivity of microorganisms to different biotic and abiotic factors.

\section{Conclusions}

Some promising general, conclusions may be derived for the results obtained here:

1. PCP removal in contaminated soil was greater than $96 \%$ in the three concentrations studied, which could be caused either by adsorption in the soil matrix, or degradation by the rhizosphere, which showed higher PCP removal in planted treatments, than unplanted soil.

2. Aerial and radical biomass decreased when the PCP concentration was increased, resulting in significant differences, especially for the $250 \mathrm{mg} \mathrm{kg}^{-1}$ treatment of PCP with the control. The dehydrogenase activity decreased when the PCP concentration was increased, showing certain negative effects on some types of microorganisms.

3. The estimation of the microbial biomass was not affected by increasing the PCP concentration. With respect to the $\beta$-glucosidase activity, there was no significant difference between diverse PCP concentrations applied to the soil, indicating a low toxicity of the contaminant due to low PCP availability in the soil matrix at the end of the assay.

4. The organic acid exudates varied during the incubation time, influenced by the stress due to the different treatments and the root distribution. Therefore, Lolium multiflorum is a promising candidate for designing field scale phytoremediation processes.

\section{Acknowledgements}

This research was financed by the FONDECYT 1050614, 1090678, CONICYT-CSIC 2007-144 and DIUFRO GAP-2007 projects. 


\section{References}

Amellal, N., Leyval, C., Joner, E.J., Corgie, S.C. 2002. Nutritional constraints to degradation of polycyclic aromatic hydrocarbons in a simulated rhizosphere. J Environ. Qual. 34, 859-864.

Cea, M., Seaman, J.C., Jara, A.A., Mora, M.L., Diez, M.C. 2005. Describing chlorophenol sorption on variable-charge soil using the triple-layer model. J Colloid. Interf. Sci. 292, 171-8.

Dams, R.I., Paton, G.I., Killham, K. 2007. Rhizoremediation of pentachlorophenol by Sphingobium chlorophenolicum ATCC 39723. Chemosphere. 68, 864-870.

Debosz, K., Rasmussen, P.H., Pedersen, A.R. 1999. Temporal variations in microbial biomass $\mathrm{C}$ and cellulolytic enzyme activity in arable soils: effects of organic matter input. Appl. Soil Ecol. 13, 209218.

Diez, M.C., Gallardo, F., Saavedra, G., Cea, M., Gianfreda, L., Alvear, M. 2006. Effect of pentachlorophenol on selected soil enzyme activities in a Chilean Andisol. J Soil Sc. Plant Nutr 6(3), 40-51.

Diez, M.C., Quiroz, A., Ureta-Zanartu, S., Vidal, G., Mora, M.L., Gallardo, F., Navia, R. 2005. Soil retention capacity of phenols from biologically pretreated kraft mill wastewater. Water Air Soil Poll 163, 325-339.

Garcia, C., Hernandez, T., Costa, F. 1997. Potential use of dehydrogenase activity as an index of microbial activity in degraded soils. Commun. Soil Sci Plan. $28,123-134$.

He, Y., Xu, J., Lv, X., Ma, Z., Wu, J., Shi, J. 2009. Does the depletion of pentachlorophenol in root-soil interface follow a simple linear dependence on the distance to root surfaces?. Soil Biol. Biochem. 41, 1807-1813.
He, Y., Xu, J., Tang, C., Wu, Y. 2005. Facilitation of pentachlorophenol degradation in the rhizosphere of ryegrass (Lolium perenne L.). Soil Biol.Biochem. 37, 2017-2024.

Madejón, E., Burgos, P., López, R., Cabrera, F. 2001. Soil enzymatic response to addition of heavy metals with organic residues. Biol. Fert. Soils 34, 144-150.

McGrath, R., Singleton, I. 2000. Pentachlorophenol transformation in soil: a toxicological assessment. Soil Biol Biochem. 32, 1311-1314.

Meade, T., D'Angelo, E. 2005. $\left[{ }^{14} \mathrm{C}\right]$ Pentachlorophenol mineralization in the rice rhizosphere with established oxidized and reduced soil layers. Chemosphere. 61, 48-55.

Mersi, W., Schinner, F. 1991. An improved and accurate method for determining the dehydrogenase activity of soils with iodonitrotetrazolium chloride.Biol. Fert. of Soils.11, 216-220.

Moreno, B., Nogales, R., Macci, C., Masciandaro, G., Benítez, E. 2011. Microbial eco-physiological profiles to estimate the biological restoration of a trichloroethylene-contaminated soil. Ecol. Indic. 11 (6), 1563-1571.

Morita, A., Horie, H., Fujii, Y., Takatsu, S., Watanabe, N., Yagi, A., Yokota, H. 2004. Chemical forms of aluminum in xylem sap of tea plants (Camellia sinensis L.). Phytochemistry. 65, 2775-2780.

Muyzer, G., Dewaal, E.C., Uitterlinden, A.G. 1993. Profiling of complex microbial populations by denaturing gradient gel electrophoresis analysis of polymerase chain reaction-amplified genes coding for $16 \mathrm{~S}$ ribosomal-RNA. Appl. Environ. Microb. 59, 695-700.

Nakamura, T., Motoyama, T., Suzuki, Y., Yamaguchi, I. 2004. Biotransformation of pentachlorophenol by Chinese chive and a recombinant derivative of its rhizosphere-competent microorganism, 
Pseudomonas gladioli M-2196. Soil Biol.Biochem. 36, 787-795.

Nannipieri, P., Ceccanti, B., Conti, C., Bianchi, D. 1982. Hydrolases extracted from soil: Their properties and activities. Soil Biol. Biochem. 14, 257-263.

Nannipieri, P., Kandeler, E., Ruggiero, P. 2002. Enzyme activities and microbiological and biochemical processes in soil. Carbon (eds R.G. Burns \& R.P. Dick), pp. 1-33. Marcel Dekker

Navia, R., Levet, L., Mora, M.L., Vidal, G., Diez, M. C. 2003. Allophanic soil adsorption system as a bleached kraft mill aerobic effluent post-treatment. Water Air Soil Poll. 148, 323-333.

Ndiaye, E.L., Sandeno, J.M., McGrath, D., Dick, R.P. 2000. Integrative biological indicators for detecting change in soil quality. Am. J. Alternative Agr. 15, 26-36.

Ouvrard, S., Lapole, D., Morel, J.L. 2006. Root exudates impact on phenanthrene availability. Water Air Soil Poll. 6, 343-352.

Qian, H., Hu, B., Cao, D., Chen, W., Xu, X., Lu, Y. 2007. Bio-safety assessment of validamycin formulation on bacterial and fungal biomass in soil monitored by real-time PCR. Bull. Environ. Contam. Toxicol. $78,239-244$.

Rattray, E.A., Prosser, J.I., Glover, L.A., Killham, K. 1995. Characterization of rhizosphere colonization by luminescent Enterobacter cloacae at the population and single-cell levels. Appl .Environ. Microbiol. 61, 2950-2957.

Rubilar, O., Feijoo, G., Diez, M.C., Lu-Chau, T.A., Moreira, M.T. Lema, J.M. 2007. Biodegradation of pentachlorophenol in soil slurry cultures by Bjerkandera adusta and Anthracophyllum discolor. Indust. Engin. Chem. Res. 46,7446751.
Rubilar, O., Tortella, G.R., Cuevas, R., Cea, M., Rodríguez-Couto, S., Diez, M.C. 2011. Adsorptive removal of pentachlorophenol by Anthracophyllum discolor in a fixed-bed column reactor. Water Air Soil Poll. DOI: 10.1007/s11270-011-1039-7.

Soto-Córdoba, S.M., Baeza, J., Freer, J. 2001. Soxhlet extraction of pentachlorophenol from soil with in situ derivatization. Bol. Soc. Chil. Quím. 46, 179185 .

Tabatabai, M.A. 1982. Methods of soil analysis part 2, in: Page, A.L., Keeney, D.R. (Eds.). Chemical and microbiological properties, 2. Soil Sci Soc Am J, Madison, pp. 922-928. 937-940.

Taylor, G. J., Foy, C.D. 1985. Mechanisms of aluminum tolerance in Triticum aestivum L. (Wheat). I. Differential $\mathrm{pH}$ induced by winter cultivars in nutrient solutions. Am. J. Bot. 72(5), 695-701.

Trasar-Cepeda, C., Leiro's, M.C., Seoane, S., Gil-Sotres, F. 2000. Limitations of soil enzymes as indicators of soil pollution. Soil Biol. Biochem. 32, 1867-1875.

Walton, B.T., Hoylman, A.M., Pérez, M. M., Anderson, T.A., Johnson, T.R., Guthrie, E.A., Christman, R.F. 1994. Rhizosphere microbial communities as a plant defense against toxic substances in soils. Bioremediation through rhizosphere technology. 563, 82-92.

Zheng, Y., Zhang, F.S. 2000. Effect of soil moisture on release of low molecular weight organic acids in root exudates and the accumulation of iron in root apoplasm of peanut. Pedosphere. 10, 333-338. 